\title{
Designing multifunctional pigments for an improved energy efficiency in buildings
}

Estibaliz Aranzabe $^{1}$, María Isabel Arriortua ${ }^{2 *}$, Aitor Larrañaga ${ }^{2}$, Ana Aranzabe ${ }^{1}$, Pedro María Villasante ${ }^{3}$, Ricard March $^{3}$.

1.- IK4-Tekniker, Surface Chemistry Unit, Calle Iñaki Goenaga, 5, 20600 Eibar, Gipuzkoa, Spain.

2.- Universidad del País Vasco (UPV/EHU), Facultad de Ciencia y Tecnología, Barrio Sarriena S/N, 48940 Leioa, Bizkaia, Spain.

3- Nubiola Pigmentos S.L., Vitoria Kalea, 19, 01400 Laudio, Araba, Spain.

\begin{abstract}
Buildings are responsible for $40 \%$ of the total energy use and $36 \%$ of total GHG emissions within the EU. Materials science offers solutions that when combined can offer energy savings in building sector. In this study, high reflectance coating and thermal storage capacity are combined with the aim of improving energy efficiency in buildings. For this issue a multifunctional pigment having a phase change material adsorbed on its surface and a high total solar reflectance has been manufactured.
\end{abstract}

The total solar reflectance of the pigment will make the paint to reflect the sunlight radiation in the infrared part of the spectrum reducing the amount of absorbed radiation. This high reflection provides a surface level effect as is a passive stimulus-responsive solution that acts with sunlight radiation.

On the other hand, the thermal storage capability provides a bulk level effect as is passive stimulus-responsive solution acting by temperature changes, making it possible to use constructive materials as a thermal energy storage media.

The preparation process is described and the pigment is characterized conveniently. The thermal performance of corresponding pigmented coatings was evaluated by a simulated experiment in which two boxes were covered with the coating containing the multifunctional pigment and traditional pigmented coating on their tops. The indoor air temperature and the interior temperature of the substrate were measured obtaining differences of $4-5^{\circ} \mathrm{C}$. 
Keywords: Multifunctional, Pigment, Total Solar Reflectance, Coating, Energy efficiency

*Corresponding author: Estibaliz Aranzabe

E-mail address: estibaliz.aranzabe@tekniker.es

IK4-Tekniker, Calle Iñaki Goenaga, 5, 20600 Eibar, Gipuzkoa, Spain.

Tel.: +34 943206744

\section{Introduction}

Buildings are responsible for $40 \%$ of the total energy use [1] and according to the European Commission $80 \%$ of the population will be living in already existing buildings by the year 2030 [2]. One measure that can contribute to improve energy sustainability is to increase the energy efficiency in existing buildings [3].

Materials industry can provide different solutions addressing building refurbishment oriented to energy savings at an affordable cost [4]. In this sense, high reflectance outdoor coatings and phase change materials are proposed as promising technologies.

Phase Change Materials (PCMs) are products capable of storing and releasing thermal energy within the temperature of the melting and freezing processes [5]. These materials are being integrated in different building components -after encapsulation process- with the aim of reducing energy consumption for space conditioning [6]. There is a need of new or modified encapsulation methods economically available [7]. A previous work presented a hexadecane/pigment composite as one promising alternative and a scalable solution when capillary impregnation method is applied $[8,9]$ and that can be integrated in commercial paints.

The cool material technology presents a cost effective passive technique that can impact directly in the energy consumption of buildings [10]. These coatings reflect sunlight radiation in the infrared part of the spectrum (the half of the solar radiation) $[11,12]$.

Combination of technologies can help to achieve a superior energy performance within buildings [13]. Both cool roof and PCM roof can help to decrease the cooling load demand [14]. A coating having high reflectivity can contribute to reduce the amount of absorbed radiation, and the PCM approach can reduce the sensible heat. 
Ultramarine blue pigment (UB) is an inorganic low-cost pigment with high pigmentary properties that is commonly used in construction sector.

The aim of this study is to develop a cool pigment based on ultramarine blue and providing thermal storage capacity. The strategy to modify this conventional pigment into a Multifunctional pigment for energy saving is to impregnate the pigment with a phase change material and coat it with a coating containing nanoparticles obtaining a pigment with high Total Solar Reflectance. This multifunctional pigment is suitable to be dispersed in different constructive materials (polymers, concrete, paint). The high reflection provided by the pigment will give to the material surface level effect acting with sunlight radiation. The thermal storage capability will give to the material a bulk level effect acting by temperature changes. The combination of both effects will contribute to energy savings in construction sector.

\section{Experimental}

\subsection{Materials and methods}

A standard ultramarine blue pigment based on the crystal chemistry of the royal blue Sodalite mineral Lazurite $\left[\mathrm{Na}_{6} \mathrm{Ca}_{2} \mathrm{Al}_{6} \mathrm{Si}_{6} \mathrm{O}_{24}\left(\mathrm{Sn}_{n}, \mathrm{SO}_{4}\right)_{2}\right]$ produced by Nubiola Pigmentos S.L. was used (Table 1 [UM]). Laboratory grade hexadecane $\left(\mathrm{C}_{16} \mathrm{H}_{34}\right)$ from Scharlab was used as the phase change material.

The Hexadecane/pigment composite was fabricated by capillary impregnation method using following process conditions: Ratio Pigment:Hexadecane of 1:1.5; a processing time of 10 minutes; a processing temperature of $25^{\circ} \mathrm{C}$ and using petroleum ether as the cleaning strategy. After the process, the pigment was dried in an oven at $60^{\circ} \mathrm{C}$ during 24 hours. The Hexadecane/pigment composite was coated with a reflecting film based on $\mathrm{TiO}_{2}$ matrix containing titania nanoparticles (consisting of $71 \%$ anatase and $27 \%$ rutile with a primary size of $21 \mathrm{~nm}$ purchased from Sigma-Aldrich). With this aim, the hexadecane/pigment composite was put in dispersion in water at $50 \mathrm{~g} / 1$. An hydrolyzed solution of titanium (IV) n-butoxide containing a $6 \%$ wt. of titania nanoparticles (with a primary size of $21 \mathrm{~nm}$ purchased from Sigma-Aldrich) was then added drop by drop to this dispersion. Once the solution was added, obtained pigments were filtered and cured at $60^{\circ} \mathrm{C}$ during 12 hours (Table $\left.1[\mathrm{MF}]\right)$. A last pigment having only the reflecting film 
around the raw pigment was fabricated (Table $1[\mathrm{~F}]$ ) to evaluate the contribution of the high TSR functionality separately.

Table 1.- Pigments dispersed in a water-based paint to be evaluated in terms of energy saving.

\begin{tabular}{|c|c|c|c|}
\hline Pigment & Description & Functionality & Effect \\
\hline UM & Un modified pigment & None & Surface level effect \\
\hline F & Functional pigment & High reflectance & Bulk level and surface level \\
MF & $\begin{array}{c}\text { Multifunctional } \\
\text { pigment }\end{array}$ & $\begin{array}{c}\text { High reflectance }+ \text { Thermal } \\
\text { storage (PCM) }\end{array}$ \\
\hline
\end{tabular}

The preparation method of the colored coating on an opaque substrate (Stainless steel) as a cool coat was the following: the pigment was mechanically dispersed at different percentages (5, 10 and 15\%wt.) in a water-based paint. Then Stainless steel substrates were painted with a layer of $50 \mu \mathrm{m}$ of thickness. The paint was applied with a Quadrangular Applicator (ASTM D 823-53) from NEURTEK which is a paint spreader of constant coat thickness. The thickness of the painted Stainless steel substrates (theoretically $50 \mu \mathrm{m}$ ) was verified by a portable instrument for measuring coating thickness (Dualscope ${ }^{\circledR}$ FMP100). The obtained results showed a high reproducibility of the layers being the thickness for UM, F and MF, 49.8(1), 50.2(1) and 50.0(1) $\mu \mathrm{m}$ respectively.

\subsection{Characterization techniques}

Total Solar Reflectance (TSR) is the percentage of irradiated energy that is reflected by an object. TSR of the painted substrates was measured in a Perkin Elmer Lambda 950 $\mathrm{UV} / \mathrm{Vis} / \mathrm{NIR}$ System in the wavelength range from 300 to $2500 \mathrm{~nm}$ according to ASTM G173and using poly-tetrafluoroethylene (PTFE) as the white standard.

The lightness (CIELAB lightness $\mathrm{L}^{*}$ ) of the painted substrates was measured in a Perkin Elmer Lambda $950 \mathrm{UV} / \mathrm{Vis} / \mathrm{NIR}$ System in the wavelength from $380 \mathrm{~nm}$ to $780 \mathrm{~nm}$. The TSR of two materials can be compared if their tinting strength (DL) is the same, so a relation between DL (lightness) and TSR for each material was established by preparing paints with different percentages of pigment.

The thermal storage capability of the pigments was tested using Differential Scanning Calorimetry measurement that was carried out using a DSC (Mettler Toledo HP 
DSC827) under nitrogen atmosphere (50 $\mathrm{ml} / \mathrm{min})$, using around $5 \mathrm{mg}$ as a sample weight in a sealed aluminum pan. A dynamic method with a temperature ranged from $-10^{\circ} \mathrm{C}$ to $50^{\circ} \mathrm{C}$ at a rate of $5^{\circ} \mathrm{C} / \mathrm{min}$ was used. Melting point, crystallization point and the latent heat of fusion and crystallization of pigments were calculated.

The thermal performance of the pigments was evaluated by using painted stainless steel substrates in a simulated experiment (with boxes) comparing UM, F and MF behavior. The evaluated effect was mainly the one related to the surface (high reflectance property) as to be capable of measuring the bulk effect; the pigment must be dispersed in a bulk material to have enough thermal storage capability.

\section{Results and discussion}

\subsection{Chromatic properties \& NIR reflectance analysis}

Total Solar Reflectance and Lightness were measured in paints containing different percentages un-modified (UM), functional (F), multifunctional pigment (MF) and the raw paint (Reference). An interior water-based paint was selected as the matrix and the pigments were mechanically dispersed. Stainless steel substrates were painted with a layer of $50 \mu \mathrm{m}$ of thickness. Table 2 below shows the materials prepared and the obtained values for DL and TSR.

Table 2.- DL and TSR of painted substrates with a water-based paint containing different percentages of $\mathrm{UM}, \mathrm{F}$ and MF pigments.

\begin{tabular}{|c|c|c|c|}
\hline Pigment & \%wt.Pigment & TSR(\%) & DL \\
\hline Reference & 0 & 80,98 & 94,61 \\
\hline \multirow{2}{*}{ UM } & 5 & 58,26 & 64,54 \\
& 10 & 53,86 & 58,94 \\
& 15 & 51,26 & 57,03 \\
\hline \multirow{2}{*}{ F } & 5 & 69,33 & 69,01 \\
& 10 & 66,78 & 64,33 \\
& 15 & 62,79 & 58,99 \\
\hline \multirow{3}{*}{ MF } & 5 & 70,52 & 69,56 \\
& 10 & 67,87 & 64,12 \\
& 15 & 63,97 & 59,49 \\
\hline
\end{tabular}

For each pigment, the linear equation relating TSR and DL was calculated (see Figure 1). 


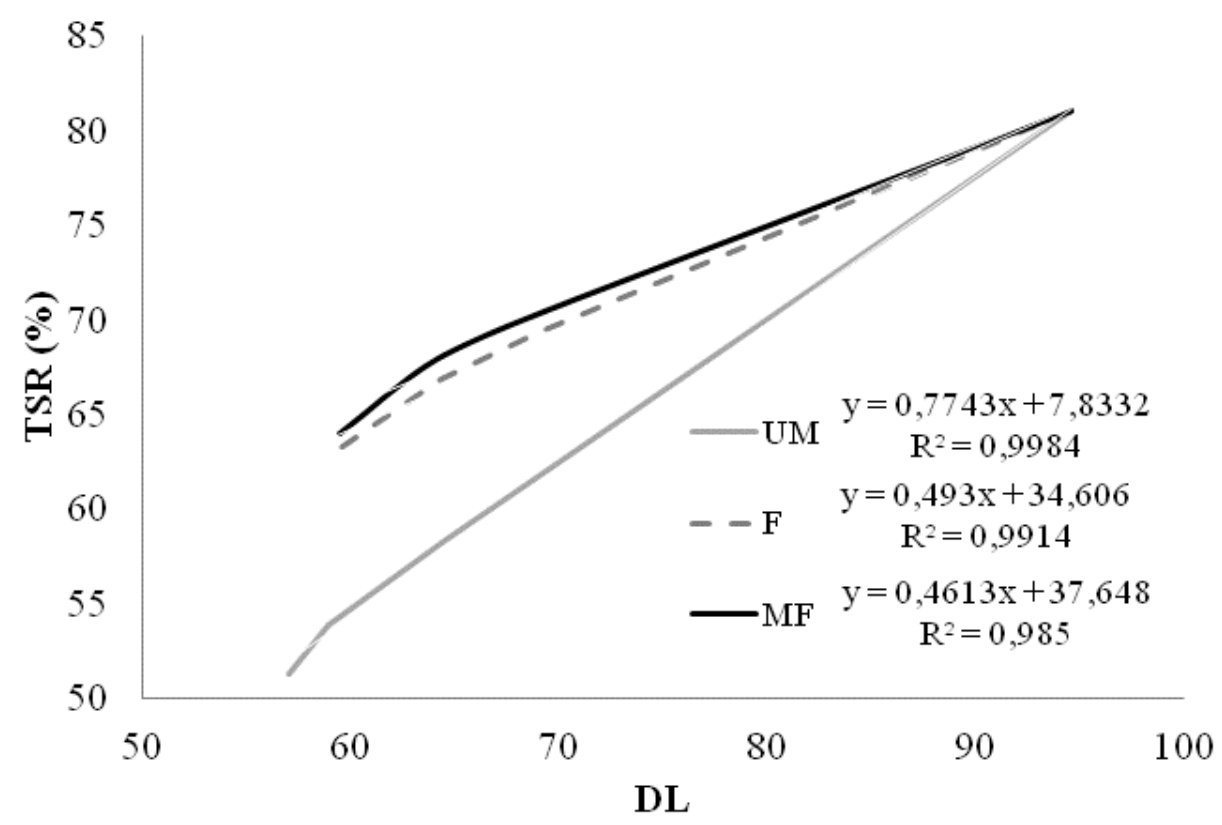

Fig.1.- Total Solar Reflectance vs DL of the paint containing the Unmodified pigment compared to the one containing F and MF pigment.

Once, the equation is defined, the TSR for a standard DL value of 65 was calculated obtaining a $58.16 \%$ of TSR for the UM pigment, $66.65 \%$ for F pigment and $67.16 \%$ for the MF pigment. The paint containing the multifunctional pigment provides a TSR a $15 \%$ higher than the one obtained with the paint containing the unmodified pigment for a standard DL of 65.

\subsection{Thermal energy storage capability}

The obtained sample (MF) was analyzed by DSC (with the conditions previously detailed) to measure the latent fusion heat and crystallization as well as the melting and crystallization point values. Table 3 summarizes the obtained thermal properties of the MF pigment compared with the properties obtained for the raw phase change material (hexadecane).

Table 3.- Thermal properties of hexadecane/pigment composites fabricated under different processing conditions.

\begin{tabular}{|c|c|c|c|c|}
\hline & $\begin{array}{c}\text { Melting } \\
\text { point }\left({ }^{\circ} \mathbf{C}\right)\end{array}$ & $\begin{array}{c}\text { Crystallization } \\
\text { point }\left({ }^{\circ} \mathbf{C}\right)\end{array}$ & $\begin{array}{c}\text { Latent heat } \\
\text { (fusion) }(\mathbf{J} / \mathbf{g})\end{array}$ & $\begin{array}{c}\text { Latent heat } \\
\text { (Crystallization) }(\mathbf{J} / \mathbf{g})\end{array}$ \\
\hline Hexadecane & 19.11 & 15.85 & 217 & 224 \\
\hline UM & --- & --- & --- & --- \\
\hline F & --- & --- & --- & --- \\
\hline MF & 18.61 & 13.41 & 37.18 & 37.21 \\
\hline
\end{tabular}


The developed multifunctional pigment provides a Latent heat of fusion of $37 \mathrm{~J} / \mathrm{g}$ (around a 17\%wt. hexadecane adsorbed in the pigment). The MF pigment starts melting at $16.5^{\circ} \mathrm{C}$ and finalizes its melting at $21^{\circ} \mathrm{C}$ (see the thermogram in Figure 2) while the raw hexadecane melts in the range between $17.5^{\circ} \mathrm{C}$ and $21^{\circ} \mathrm{C}$.

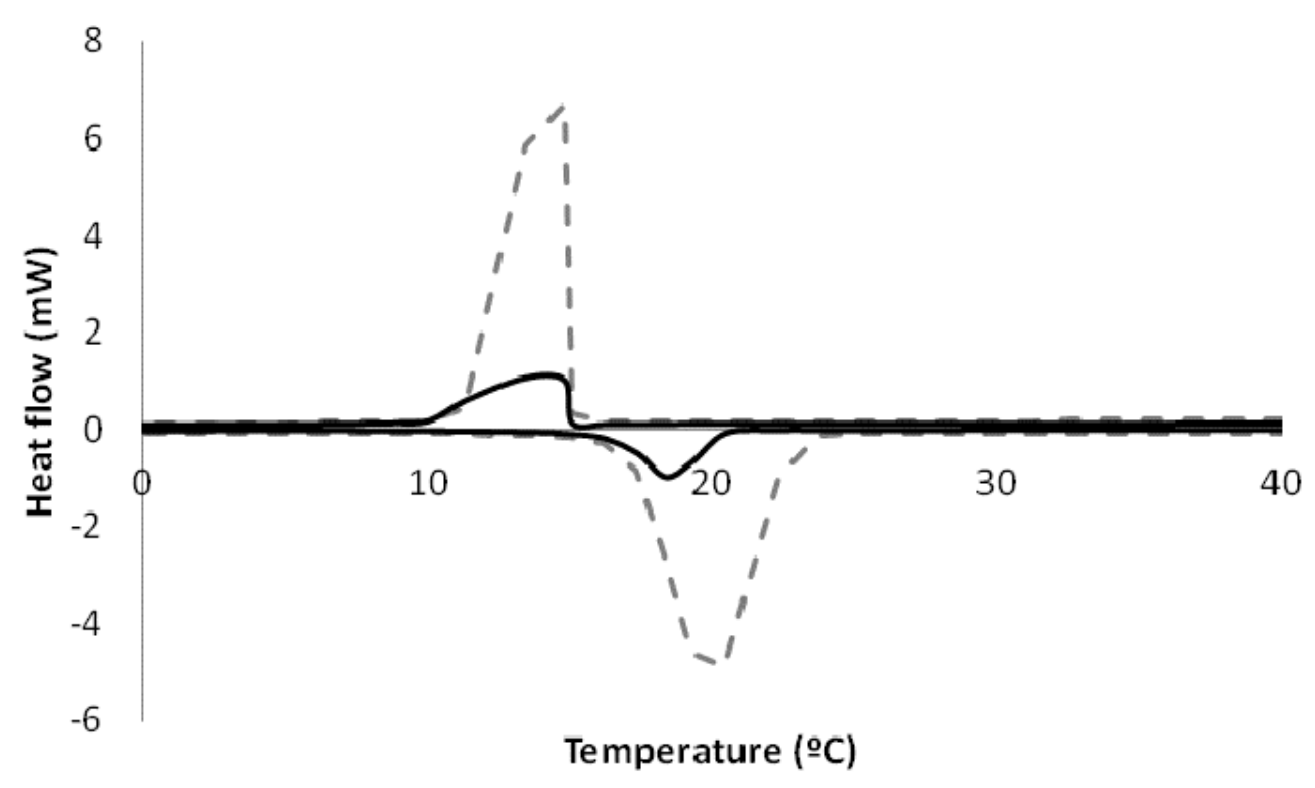

Fig.2.- Differential Scanning Calorimetry analysis of MF pigment compared with the raw phase change material (hexadecane).

The recommended temperature values in EN 15251:2007 are $20^{\circ} \mathrm{C}$ and $26^{\circ} \mathrm{C}$ for winter and summer respectively. Since most of the energy is spent for heating purposes, rather than for cooling, a PCM with a freezing/melting range around $20^{\circ} \mathrm{C}$ is adequate, so $\mathrm{MF}$ pigment is a promising candidate for building energy efficiency.

\subsection{Effect of cool colored coating testing the inside air temperature}

ABS (Acrylonitrile butadiene styrene) boxes $(4 x 4 x 4 \mathrm{~cm})$ were manufactured and covered with colored stainless steel substrate on their top. An infrared lamp (Philips, BR125IRRed, 250W), was put above the box being the distance between lamp bottom and the box top $30 \mathrm{~cm}$, the boxes were irradiated during 20 minutes. Hand Held Four Channel Type K Thermocouple Datalogger with a PFA insulated thermocouple with an operating range from $-75^{\circ} \mathrm{C}$ to $+250^{\circ} \mathrm{C}$, a resolution of $0.1^{\circ} \mathrm{C}$ and an accuracy of $\pm 0.2 \%$ of reading, was used to record interior air temperature of the centre or the box $\left(\mathrm{T}_{2}\right)$ and also to measure the interior surface of the roof $\left(\mathrm{T}_{1}\right)$ (see Figure 3 ). 


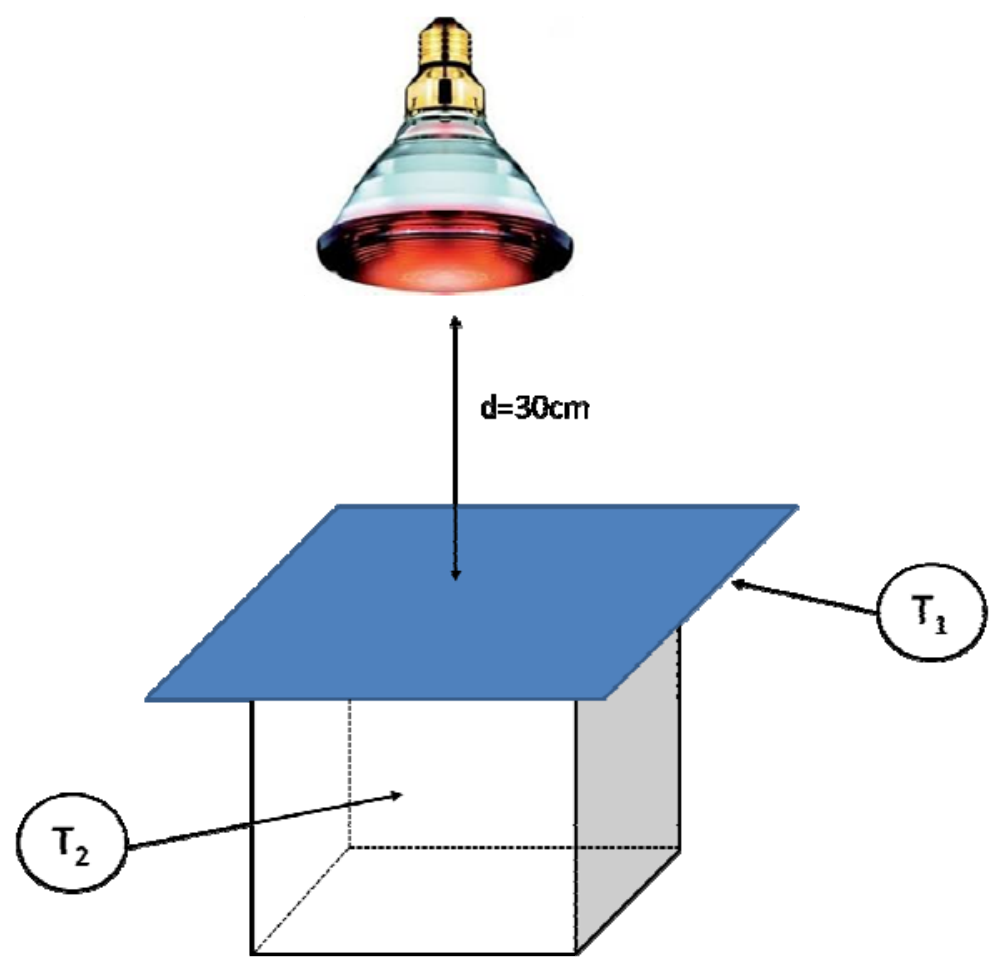

Fig.3.- The set up for testing thermal performance showing the situation of the thermocouples and the distance between lamp and roof.

In order to evaluate the thermal performance of the developed pigments at surface level, a substrate painted with a paint containing the unmodified pigment was tested and also a substrate painted with a paint containing the $\mathrm{F}$ and MF pigment were tested in the same conditions. As has been explained before, the Solar Reflection of two materials can be compared if their tinting strength (DL) is the same. For this reason, paints with the same DL were prepared being necessary to use different percentages of pigment on each case (see Table 4).

Table 4.- Tested substrates by the simulated experiment.

\begin{tabular}{|c|c|c|c|}
\hline Pigment & \%wt.Pigment & TSR(\%) & DL \\
\hline UM & 5 & 58,26 & 64,54 \\
\hline F & 10 & 66,78 & 64,33 \\
\hline MF & 10 & 67,87 & 64,12 \\
\hline
\end{tabular}

The results of the experimental simulation conducted under the same condition, are shown in Figure 4. 


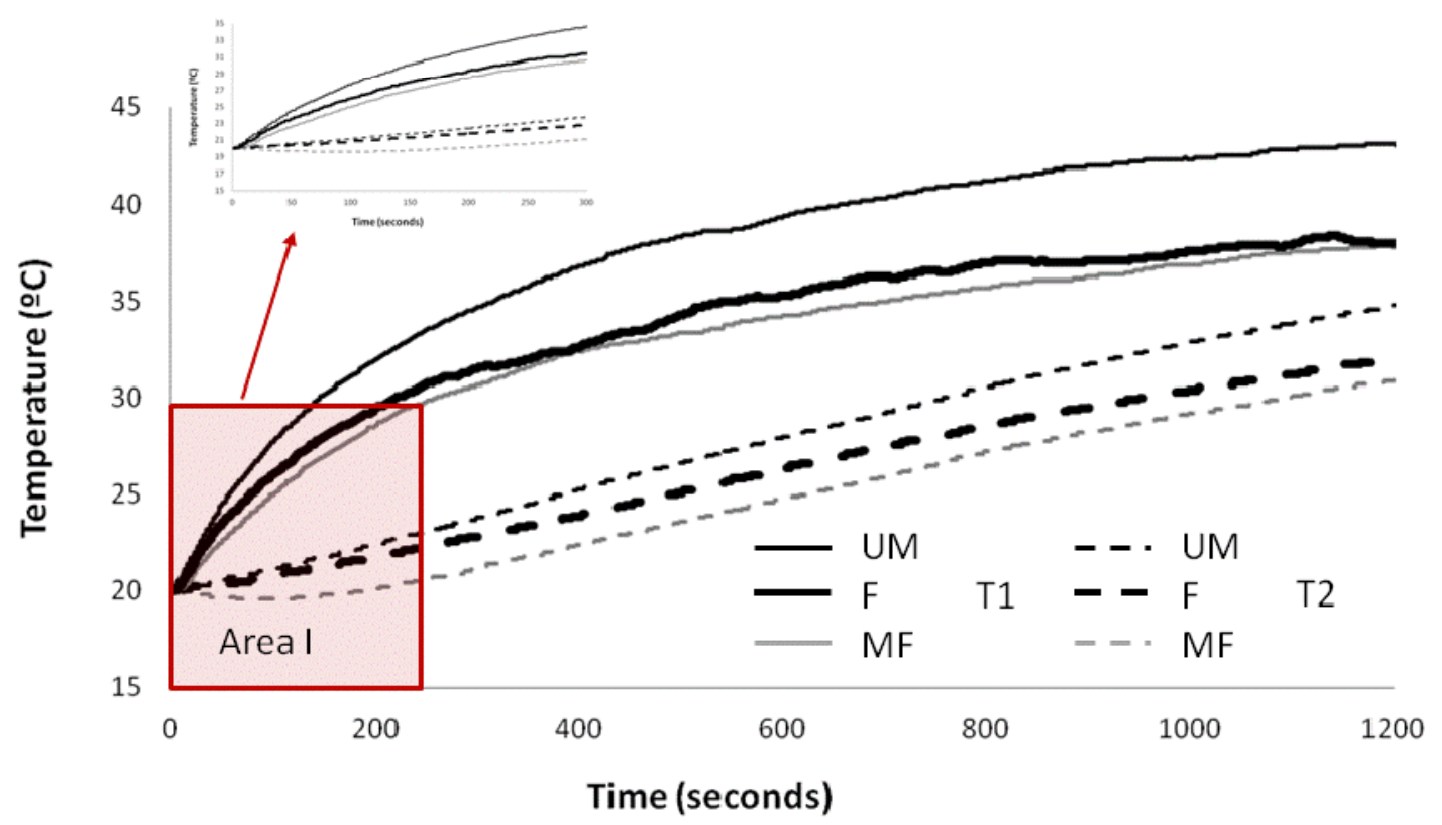

Fig.4.- Roof interior temperature $\left(\mathrm{T}_{1}\right)$ and Interior air temperature $\left(\mathrm{T}_{2}\right)$ of boxes covered with paint containing UM, F and MF pigment.

The interior surface of the roof $\left(\mathrm{T}_{1}\right)$ increased gradually being $43.1^{\circ} \mathrm{C}$ the temperature at the end of the test for the $\mathrm{UM}, 38.0^{\circ} \mathrm{C}$ for $\mathrm{F}$ and $37.8^{\circ} \mathrm{C}$ for the $\mathrm{MF}$ pigment. The interior air temperature difference $\left(\mathrm{T}_{2}\right)$ increased gradually being $34.8^{\circ} \mathrm{C}$ the final temperature for the UM, 31.9 for $\mathrm{F}$ and $31^{\circ} \mathrm{C}$ the one for the MF pigment. At the beginning of the test (Area I), a plateau region can be observed (during the first 200 seconds of the experiment) coincident with the melting range of the phase change material contained in the MF pigment (finalizes its melting at $21^{\circ} \mathrm{C}$ ).

This test was designed to measure mainly the surface level effect (the effect related to the total solar reflectance) as the stainless steel substrates were painted with a layer of $50 \mu \mathrm{m}$ of thickness being too thin to observe any bulk effect.

Table 5 shows the recorded temperature for each substrate after the 20 minutes of the experiment.

Table 5.- Recorded temperatures (interior surface of the roof $\left(T_{1}\right)$ and interior air temperature $\left(T_{2}\right)$ at the end of the simulated test).

\begin{tabular}{|c|c|c|c|}
\hline Temperature & UM & F & MF \\
\hline Interior surface of the roof $\left(\mathrm{T}_{1}\right)$ & 43.1 & 38.0 & 37.8 \\
\hline Interior air temperature $\left(\mathrm{T}_{2}\right)$ & 34.8 & 31.9 & 31 \\
\hline
\end{tabular}


The interior surface of the roof $\left(T_{1}\right)$ and the interior air temperature $\left(T_{2}\right)$ differences increased gradually in all the cases. As was expected, the main contribution for the thermal regulation effect is provided by the high reflectance property of the pigment. More than the $75 \%$ of the temperature reduction of the interior air temperature $\left(\mathrm{T}_{2}\right)$ is given by the Solar Reflectance of the pigment. This issue is explained by the low latent heat given by the phase change material to the final material due to the thickness of the paint. As was explained before, the high reflection provides surface level effect acting with sunlight radiation and the thermal storage capability provides a bulk level effect acting by temperature changes (Figure 5).

MF pigment dispersed in a BULK material

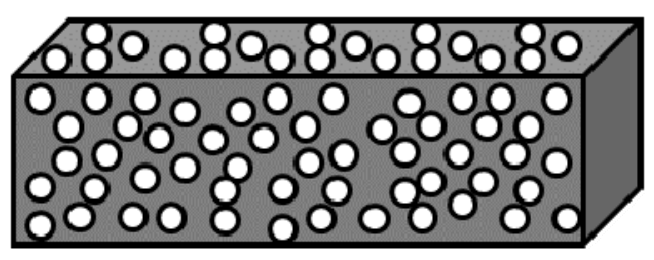

BULK EFFECT (PCM):

Stimuli = temperature $+$

SURFACE EFFECT

(TSR): Stimuli $=$ light

\section{MF pigment dispersed in a COATING}

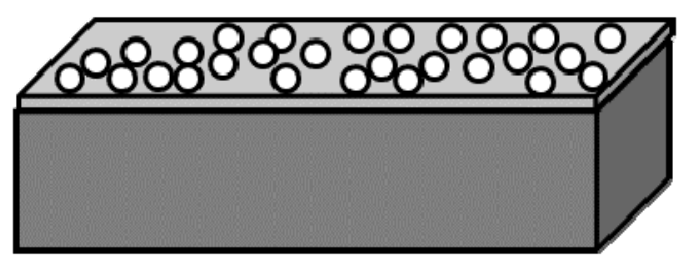

SURFACE EFFECT

(TSR): Stimuli = light

Fig.5.- Bulk effect and Surface effect provided by the MF pigment

Nevertheless, the bulk effect of a pigment containing phase change material was previously tested once dispersed in a $17 \mathrm{wt} . \%$ content in an epoxy resin. A sandwich panel for a mock-up with a volume of $9 \mathrm{~m}^{3}$ was constructed obtaining a energy saving of $7.4 \%$ respect to a sandwich panel containing a UM pigment when a test for maintaining the selected set point $\left(23^{\circ} \mathrm{C}\right)$ by an electrically-supplied heating device was carried out. The durability of the pigment containing the phase chase material was also assessed by testing its long term degradation behavior against time and against cycling [8,9].

\section{Conclusions}

In this study, a multifunctional pigment based on ultramarine blue pigment, having a high reflectance and thermal storage capacity has been developed. Hexadecane/pigment composite was fabricated by capillary impregnation and was further coated with a reflecting film based on $\mathrm{TiO}_{2}$ matrix containing titania nanoparticles. The developed 
multifunctional pigment provides a Latent heat of fusion of $37 \mathrm{~J} / \mathrm{g}$ and a paint containing the multifunctional pigment provides a TSR a $15 \%$ higher than a paint containing the unmodified pigment (for a standard DL of 65).

The thermal performance of the pigment was evaluated and compared with the reference by using painted stainless steel substrates in a simulated experiment. A difference on the interior air temperature of $4^{\circ} \mathrm{C}$ was obtained while a temperature difference of $5.3^{\circ} \mathrm{C}$ was obtained for the interior surface of the roof.

Although the test was designed to measure the surface level effect (high reflection), the contribution of each functionality (thermal storage and high reflection) to the thermal regulation effect was proved. In the tested conditions, more than the $75 \%$ of the interior air temperature reduction $\left(\mathrm{T}_{2}\right)$ is associated to the Solar Reflectance of the pigment.

\section{Acknowledgement}

This project has received founding from the European Union Seventh Framework Programme (FP7-NMP-2010-Small-5) under grant agreement $n^{\circ} 280393$ and from the Dpto. Educación, Política Lingüística y Cultura of the Basque Goverment (IT-630-13), Ministerio de Ciencia e Innovación (MAT2013-42092-R) and Engineering and Physical Sciences Research Council (EP/I003932). SGIker technical support (UPV/EHU, MEC, GV/EJ, European Social Fund) is gratefully acknowledged.

\section{REFERENCIAS}

[1] Ramírez-Villegas, R., et al. (2016). "Assessment of renovation measures for a dwelling area - Impacts on energy efficiency and building certification." Building and Environment 97: 26-33.

[2] European Commission, EUR 24283-energy-efficient Buildings PPP Multiannual Roadmap and Longer Term Strategy, 2010, http://dx.doi.org/10.2777/10074. Luxembourg.

[3] Tan, B., et al. (2016). "Optimal selection of energy efficiency measures for energy sustainability of existing buildings." Computers \& Operations Research 66: 258-271.

[4] "Innovative Chemistry for Energy Efficiency of Buildings in Smart Cities" L. Bax, J. Cruxent, J. Komornicki, European Technology Platform for Sustainable Chemistry and SmartCities and Communities (2013).

[5] Y. Chena, Y. Shiha, Y. Yub, International Journal of Applied Science and Engineering 11 (2013), 2, 227233.

[6] M. Faraji, M.E. Alami, M. Najam, Journal of Mathematics and Computer Science 10 (2014), 212-227.

[7] X. Li, J. Sanjayan, J. Wilson, Energy and Buildings 76 (2014) 284-294.

[8] Aranzabe, E., Villasante, P.M., March, R., Arriortua, M.I., Larrañaga, A. and Aranzabe, A. (2015); Physics and Chemistry, 5, 171-184.

[9] Aranzabe, E., Arriortua, M.I., ., Larrañaga, A., Villasante, P.M., Aranzabe, A. and March, R.; American Journal of Chemistry and Applications, Vol. 2, No. 4, 2015, pp. 98-105. 
[10] Mastrapostoli, E., et al. (2014). "On the cooling potential of cool roofs in cold climates: Use of cool fluorocarbon coatings to enhance the optical properties and the energy performance of industrial buildings." Energy and Buildings 69: 417-425.

[11] X. Zhao, Y. Zhang, Y. Huang, H. Gong, J. Zhao, Dyes and Pigments 116 (2015) 119-123.

[12] J. A. Prakash, S. Laha, S. Natarajan, M.L. Reddy, Dyes and Pigments 107 (2014) 118-126.

[13] ChuaKJ,ChouSK,YangWM,YanJ.Achievingbetterenergy-efficient air conditioning - a reviewoftechnologiesandstrategies.ApplEnergy 2013;104:87-104.

http://dx.doi.org/10.1016/j.apenergy.2012.10.037.

[14] Roman, K. K., et al. (2016). "Simulating the effects of cool roof and PCM (phase change materials) based roof to mitigate UHI (urban heat island) in prominent US cities." Energy 96: 103-117. 